\title{
Serum biochemical profiles of repeat breeder holstein friesian cows
}

\author{
Moo Young Jung, Seogjin Kang, Dong-Hyeon Lim, Tae-ll Kim, Kyoungseok Lee, Seungmin Ha* \\ Department of Animal Resource Development, Dairy Science Division, National Institute of Animal Science, Rural Development \\ Administration, Cheonan 31000, Korea
}

Received December 12, 2021

Accepted December 27, 2021

Corresponding author:

Seungmin $\mathrm{Ha}$

E-mail: justusha@korea.kr

https://orcid.org/0000-0002-5152-1979
The fertility of dairy cows has been declining worldwide. The number of services per conception has increased, and repeat breeder (RB) cows are considered important in the dairy industry. However, there has been little research on RB cows in Korea. The objective of this study was to investigate the relationship between serum biochemical profiles and RB Holstein cattle in Korea and compare the results with those of studies conducted abroad. In addition, we investigated hidden factors that are needed for RB cattle to become pregnant. Overall, 34 Korean Holstein Friesian cows were divided into three groups: pregnant with normal cycling (PNC), pregnant with repeat breeder (PRB), and non-pregnant with repeat breeder (NRB). Blood samples were collected from the jugular vein, and serum parameters (ALT, AST, ALP, GGT, LD, CK, TP, ALB, GLOB, TBIL, BUN, CRE, GLU, TC, TG, NEFA, CA, MG, and IP) were analyzed. GGT levels were significantly different among groups $(P=0.01)$. The concentration of GGT was the highest in the NRB and the lowest in the PNC. In contrast to the findings of other studies, there were no differences in GLU, TP, TC, and BUN levels. This study is the first to investigate serum biochemistry in RB cattle and provides results that differ from those of previous studies; these findings would help establish a novel approach to improve fertility of $\mathrm{RB}$ cattle.

Key Words: Cattle, Fertility, Pregnancy, Biochemistry, Gamma-glutamyltransferase

\section{INTRODUCTION}

The fertility of dairy cows has been declining worldwide. High milk production is thought to be negatively associated with cow fertility (Lucy, 2001). Milking frequency, artificial insemination (AI) techniques, inseminating bulls, age, and repeat breeder (RB) cows could also impair the fertility of cows (García-Ispierto et al, 2007). Lucy (2001) reported that the number of services per conception has increased, making RB cows an important subject in the dairy industry. RB cows are those which are sub-fertile and without anatomical or infectious abnormalities, that do not become pregnant after at least 3rd breeding attempts (Dochi et al, 2008). They cause economic losses by increasing the costs of inseminations and expanding the calving intervals (Bonneville-Hébert et al, 2011).

Several measures have been undertaken to improve the fertility of cattle. Some researchers have focused on endocrine system dysfunction, such as abnormal levels of progesterone, estradiol, and luteinizing hormones (Båge et al, 2002). However, their fertility has not improved, even though RB cows are treated with these hormones (Katagiri and Moriyoshi, 2013). In another study in Sudan, intra-uterine infusion of iodine compounds reduced the service per conception in $\mathrm{RB}$ cows (Omer, 2008). However, this research has not been conducted in a clean environment; $93 \%$ of the patients had bacterial uterine infections. Other researchers have used embryo transfer to overcome fertilization failure 
and early embryo loss in RB cows (Ambrose et al, 1999). Fertility rates were significantly increased when embryos were transferred following AI (Dochi et al, 2008). Embryo transfer could be a solution to infertility in RB cows, but it requires additional costs.

Research has been conducted on the relationship between serum metabolites and RB cows. RB cows showed lower glucose (GLU) levels, but similar total protein (TP) and total cholesterol (TC) levels compared with fertile cows (Guzel and Tanriverdi, 2014). In another study, elevated plasma levels of urea were observed in RB cows (Kurykin et al, 2011). In Korea, although there are data on the relationships between selected metabolites and the resumption of cyclicity in dairy cows, the relationship between serum metabolites and RB has not been investigated. Existing research shows that non-esterified fatty acids (NEFA) were higher, and TC was lower in non-cycling cows than in cycling cows (Jeong et al, 2015). Moreover, in this study, albumin (ALB), blood urea nitrogen (BUN), and magnesium (MG) levels were lower, especially in the postpartum period.

In this study, we investigated the serum biochemical profiles of RB cows in Korean Holsteins and the hidden factors that are needed for RB cows to become pregnant. This would contribute to the improvement of dairy cow fertility and the economic income from dairy farms.

\section{MATERIALS AND METHODS}

\section{Animals}

This study was conducted in a loose housing farm located in Cheonan, Republic of Korea. Thirty-four nonmilked cows were recruited for this study. The cows were fed with carbohydrates and roughage. To prove these animals' reproductive possibilities, cows that had calved at least once were used. The cows were inseminated in the same year.

All dairy cows were maintained in standard guideline, and the experimental protocol involved in this experi- ment was approved by the Institutional Animal Care and Use Committee (approval number: NIAS20191526).

\section{Blood sampling and analysis}

Blood was sampled through the jugular vein by a veterinarian on August 4, 2021. All samples were collected in serum-separating tubes and delivered to the laboratory at the National Institute of Animal Science in Cheonan, Republic of Korea. The serum was separated from whole blood by centrifugation at 3,000 rpm for 10 min. Biochemical analysis was performed using a biochemistry automatic analyzer (Hitachi 7180, Hitachi Ltd., Tokyo, Japan). A total of 19 serum parameters were analyzed: alanine aminotransferase (ALT), aspartate transaminase (AST), alkaline phosphatase (ALP), gamma-Glutamyltransferase (GGT), lactate dehydrogenase (LD), creatinine kinase (CK), TP, ALB, globulin (GLOB), total bilirubin (TBIL), BUN, creatinine (CRE), GLU, TC, triglyceride (TG), NEFA, calcium (CA), MG, and inorganic phosphate (IP). GLOB levels were calculated as the difference between TP and ALB levels.

\section{Case definition and study design}

Cows described as having 'normal cycling' were able to become pregnant within three inseminations, whereas repeat breeder cows fail to become pregnant following at least three inseminations, despite no clinical abnormalities. The cows were divided into three groups: (1) pregnant cows with normal cycling (PNC, n=10), (2) pregnant cows with repeat breeders (PRB, $n=8$ ), and (3) non-pregnant cows with repeat breeders (NRB, $n=16$ ). Pregnancy examination was conducted using ultrasound examination from a veterinarian 60 days after AI.

\section{Statistical analyses}

Statistical analyses were performed using $\mathrm{R}$ software (version 4.1.0; R Foundation, Vienna, Austria). This software was used to compare the mean levels of each 
factor for biochemical analysis among the groups. Before comparison, the Shapiro-Wilk normality test was conducted for each factor, of which eight factors did not show normality (MG, ALP, AST, AST, TC, GGT, CK, IP, NEFA). For these factors, the Kruskal-Wallis $\mathrm{H}$ test was used to compare the means among the groups. The other factors were checked for homogeneity of variance, and two factors did not show homogeneity (BUN, TBIL) for which Welch ANOVA test was used. One-way ANOVA test was used for the others. Multiple comparisons were performed.

\section{RESULTS}

\section{Descriptions for each group}

Primiparous cows were not used in this study. All cows had experienced calving to validate reproductive health, even though the parity was different among the groups. The PNC calved more times than PRB and NRB. NRB was the oldest group, whereas PRB was the young-
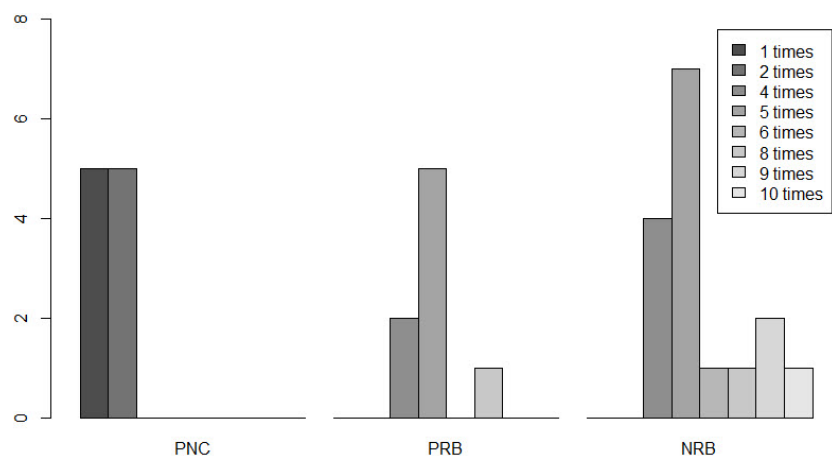

Fig. 1. Times of AI undergone. In this graph, y axis shows the number of cows. PNC cows undergone AI less than 3 times. However, PRB and NRB cows undergone AI more than 3 times. est group. However, the differences in calving time and age were not significant. Each group had significantly different AI times (Fig. 1). This number was calculated as the trying time until pregnancy in the PNC and PRB groups; otherwise, it was calculated as the number of times the patient had undergone the procedure until the day of sampling. The PNC experienced lower AI times than the other groups (Table 1).

\section{Serum profiles of each group}

To assess the serum enzymes, we analyzed the ALT, AST, ALP, GGT, LD, and CK levels. The serum biochemistry results indicated significant differences in the level of GGT $(P=0.01)$; it was lowest in PNC and highest in NRB (Fig. 2). The levels of GGT in all groups were within the reference ranges. When applied to multiple comparisons, PNC and NRB showed significant differences in GGT levels ( $P=0.01)$, PNC and PRB $(P=0.18)$, and PRB and NRB $(P=0.38)$. On the other hand, other serum en-

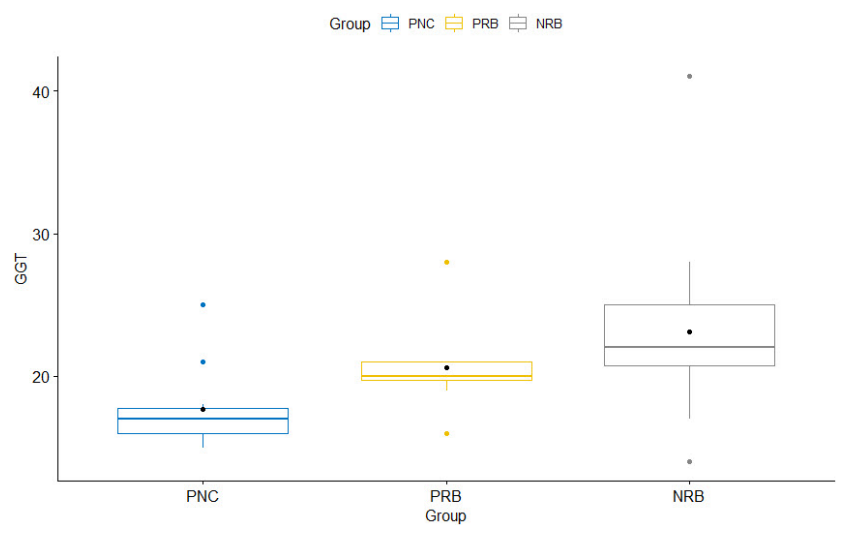

Fig. 2. The level of GGT of each group. Box graph shows the descriptions of each group. Dots outside of the boxes show the outlier. Black dots show the mean of each group.

Table 1. Descriptions for each group.

\begin{tabular}{|c|c|c|c|c|c|}
\hline \multirow{2}{*}{ Group } & PNC & PRB & NRB & \multirow{2}{*}{$\begin{array}{c}\text { Statistical } \\
\text { method }\end{array}$} & \multirow{2}{*}{$P$-value } \\
\hline & Number $=10$ & Number $=8$ & Number $=16$ & & \\
\hline Parity & $2.60 \pm 1.78(1 \sim 5)$ & $1.62 \pm 0.74(1 \sim 3)$ & $1.88 \pm 1.26(1 \sim 5)$ & Kruskal & 0.49 \\
\hline Age (year) & $5.80 \pm 0.87(3 \sim 10)$ & $5.00 \pm 0.50(3 \sim 7)$ & $6.75 \pm 0.43(4 \sim 10)$ & Kruskal & 0.11 \\
\hline Times of AI & $1.50 \pm 0.53(1 \sim 2)$ & $5.12 \pm 1.25(4 \sim 8)$ & $5.81 \pm 2.01(4 \sim 10)$ & Kruskal & $<0.001$ \\
\hline
\end{tabular}

Data are presented as mean \pm standard of error of the means (minimum $\sim$ maximum). 
zymes, such as ALT, AST, ALP, LD, and CK, did not show any differences among the groups. These levels in all groups did not exceed the reference range (Table 2).

To assess the function of organs such as the liver, gall bladder, and kidney, we analyzed TP, ALB, GLOB, TBIL, BUN, and CREA. There were no significant differences between groups. PRB had the lowest level of TP due to the lowest level of GLOB. PNC had the lowest level of ALB, whereas NRB had the highest level of ALB. The mean concentrations of TBIL in PRB and NRB were the same and lower than those in the PNC. NRB showed the highest levels of BUN, whereas PRB had the lowest level. CREA was similar in each group (Table 3).

GLU, TC, TG, and NEFA were analyzed to assess the metabolism of GLU and lipids. There were no significant differences between groups. GLU was highest in PRB but lowest in NRB. TC levels in the PRB were lower than those in the PNC and NRB, which were similar. The TG levels in each group demonstrated similarity. The mean concentration of NEFA in the PNC group was higher than that in the PRB and NRB (Table 4).

We analyzed the serum minerals CA, MG, and IP. There were no significant differences between groups. The concentration of MG was the highest in the PRB and the lowest in the PNC. The concentration of CA was the highest in the PNC and the lowest in the NRB. The concentration of IP was the highest in the PNC and the lowest in the NRB (Table 5).

Table 2. The levels of enzymes in each group

\begin{tabular}{|c|c|c|c|c|c|}
\hline & PNC & PRB & NRB & $\begin{array}{c}\text { Statistical } \\
\text { method }\end{array}$ & $P$-value \\
\hline GGT & $17.70 \pm 3.01(15.49 \sim 19.91)$ & $20.63 \pm 3.38(17.80 \sim 23.45)$ & $23.13 \pm 5.88(19.99 \sim 26.25)$ & Kruskal & 0.01 \\
\hline ALT & $25.60 \pm 6.60(20.88 \sim 30.32)$ & $23.75 \pm 4.65(19.86 \sim 27.64)$ & $23.44 \pm 6.18(19.15 \sim 25.73)$ & ANOVA & 0.44 \\
\hline AST & $64.60 \pm 9.59(57.74 \sim 71.46)$ & $59.75 \pm 6.88(54.00 \sim 65.50)$ & $60.88 \pm 8.30(56.45 \sim 65.30)$ & Kruskal & 0.59 \\
\hline ALP & $158.10 \pm 74.82(104.58 \sim 211.62)$ & $118.25 \pm 22.32(99.59 \sim 136.91)$ & $132.94 \pm 36.46(113.51 \sim 152.37)$ & Kruskal & 0.33 \\
\hline LD & $1021.70 \pm 128.30(929.92 \sim 1113.48)$ & $1055.63 \pm 178.53(906.37 \sim 1204.88)$ & $1044.38 \pm 87.42(997.79 \sim 1090.96)$ & ANOVA & 0.84 \\
\hline CK & $138.70 \pm 80.36(81.22 \sim 196.18)$ & $110.63 \pm 56.29(63.56 \sim 157.69)$ & $102.75 \pm 26.24(88.77 \sim 116.73)$ & Kruskal & 0.22 \\
\hline
\end{tabular}

Data are presented as mean \pm standard of error of the means ( $95 \%$ confidence interval lower limit $\sim$ upper limit).

Table 3. The levels of serum proteins, TBIL, BUN and CREA

\begin{tabular}{|c|c|c|c|c|c|}
\hline & $\mathrm{PNC}$ & PRB & NRB & Statistical method & $P$-value \\
\hline $\mathrm{TP}$ & $8.19 \pm 0.69(7.7 \sim 8.68)$ & $7.89 \pm 0.53(7.44 \sim 8.33)$ & $8.34 \pm 0.43(8.11 \sim 8.57)$ & ANOVA & 0.17 \\
\hline ALB & $3.67 \pm 0.33(3.43 \sim 3.91)$ & $3.79 \pm 0.28(3.55 \sim 4.02)$ & $3.83 \pm 0.24(3.70 \sim 3.95)$ & ANOVA & 0.39 \\
\hline GLOB & $4.52 \pm 0.74(3.99 \sim 5.05)$ & $4.10 \pm 0.47(3.71 \sim 4.49)$ & $4.51 \pm 0.59(4.20 \sim 4.83)$ & ANOVA & 0.26 \\
\hline TBIL & $0.089 \pm 0.038(0.062 \sim 0.116)$ & $0.070 \pm 0.018(0.055 \sim 0.085)$ & $0.070 \pm 0.015(0.062 \sim 0.078)$ & Welch ANOVA & 0.35 \\
\hline BUN & $9.24 \pm 1.87(7.90 \sim 10.58)$ & $8.69 \pm 1.77(7.21 \sim 10.16)$ & $9.50 \pm 0.87(9.04 \sim 9.96)$ & Welch ANOVA & 0.49 \\
\hline CREA & $1.326 \pm 0.219(1.167 \sim 1.483)$ & $1.325 \pm 0.224(1.138 \sim 1.513)$ & $1.346 \pm 0.181(1.250 \sim 1.443)$ & ANOVA & 0.96 \\
\hline
\end{tabular}

Data are presented as mean \pm standard of error of the means ( $95 \%$ confidence interval lower limit $\sim$ upper limit).

Table 4. The levels of nutrient metabolites (GLU, TG, TC and NEFA)

\begin{tabular}{lccccc}
\hline & PNC & PRB & NRB & $\begin{array}{c}\text { Statistical } \\
\text { method }\end{array}$ & $\begin{array}{c}P \text {-value } \\
\text { GLU }\end{array}$ \\
TG & $35.50 \pm 7.93(29.82 \sim 41.18)$ & $36.25 \pm 5.45(31.70 \sim 40.80)$ & $31.81 \pm 7.42(27.86 \sim 35.77)$ & ANOVA & 0.27 \\
TC & $23.00 \pm 6.91(18.06 \sim 27.94)$ & $22.38 \pm 5.15(18.07 \sim 26.68)$ & $24.56 \pm 7.58(20.52 \sim 28.60)$ & ANOVA & 0.27 \\
NEFA & $96.90 \pm 20.40(82.30 \sim 111.50)$ & $94.13 \pm 34.31(65.44 \sim 122.81)$ & $96.38 \pm 14.85(88.46 \sim 104.29)$ & Kruskal & 0.33 \\
\hline
\end{tabular}

Data are presented as mean \pm standard of error of the means ( $95 \%$ confidence interval lower limit $\sim$ upper limit). 
Table 5. The levels of serum minerals (CA, MG and IP)

\begin{tabular}{|c|c|c|c|c|c|}
\hline & $\mathrm{PNC}$ & PRB & NRB & Statistical method & $P$-value \\
\hline $\mathrm{CA}$ & $9.66 \pm 0.48(9.32 \sim 10.00)$ & $9.64 \pm 0.55(9.18 \sim 10.10)$ & $9.51 \pm 0.29(9.35 \sim 9.66)$ & ANOVA & 0.61 \\
\hline MG & $2.19 \pm 0.25(2.01 \sim 2.37)$ & $2.28 \pm 0.18(2.13 \sim 2.42)$ & $2.25 \pm 0.18(2.15 \sim 2.35)$ & Kruskal & 0.86 \\
\hline IP & $5.24 \pm 1.16(4.41 \sim 6.07)$ & $5.05 \pm 1.27(3.99 \sim 6.11)$ & $4.61 \pm 0.98(4.09 \sim 5.13)$ & Kruskal & 0.25 \\
\hline
\end{tabular}

Data are presented as mean \pm standard of error of the means $(95 \%$ confidence interval lower limit $\sim$ upper limit).

\section{DISCUSSION}

This study was conducted to identify the differences in serum biochemical parameters among cows during pregnancy or repeat breeding. Our results showed that elevated GGT levels were associated with NRB. Elevated GGT was shown at calving in cows, which has worse genetic merit for fertility and longer postpartum anestrous intervals (Grala et al, 2021). In addition, GGT is associated with damage to bile ducts and hepatic cells, including fasciolosis, ketosis, angiomatosis, and cholestasis (Meissonnier and Rousseau, 1976). From this point of view, the liver of NRB could be in load of clearance or biliary disorders. NRB showed significantly higher GGT levels than PNC, whereas PRB had considerably higher GGT levels than PNC. Elevated GGT levels might be one of the primary reasons for RB syndrome. This is consistent with a previous study, which indicated that bile acid synthesis may be reduced in repeat breeder cows due to hepatic abnormalities.

In contrast to GGT, other enzymes have lower sensitivity to liver damage in cattle. The hepatocytes of cattle have low ALT levels. AST, LD, and CK activities are increased not only by hepatocyte damage but also by muscle damage. GGT has better diagnostic sensitivity than ALP for biliary disorders in cattle. Thus, there is little research on the relationship between these enzymes, except for GGT and fertility. The association between AST levels and reproduction is controversial. Elevated AST activity in the postpartum period is related to delayed resumption of cyclicity (Samarütel et al, 2008). However, other studies have shown no relationship between AST and the resumption of cyclicity (Jeong et al, 2015). One study demonstrated no differences in LD and
AST between RB and early lactation cows (Kurykin et al, 2011). In our study, there was no significant relationship between ALT, AST, LD, CK, and RB cows.

A previous study in Turkey showed that normal cows have similar but lower levels in RB cows (Guzel and Tanriverdi, 2014). Comparing PNC with PRB, the level of TP corresponds to the previous study. However, NRB showed the highest level among the three groups, which is not consistent with Guzel's results. Previous studies on other breed cows showed controversy regarding the levels of total protein; RB cows showed lower or similar levels of TP (Amle et al, 2014; Ahmed et al, 2017). In our study, PNC, PRB, and NRB had low levels of ALB. A previous study reported that lower ALB levels were associated with lower fertility (Jeong et al, 2015). Our results are the opposite of this study. This was due to the study design. Considering that there was a difference in ALB only postpartum in the previous study, our results are understandable. Overall, it is difficult to conclude that there is an association between proteins and RB.

Plasma urea levels were higher in RB cows than in early lactation cows (Kurykin et al, 2011). Moreover, an association between elevated urea levels and decreased conception rates have been demonstrated (Butler et al, 1996; Sinclair et al, 2000; Rajala-Schultz et al, 2001; Dawuda et al, 2002). However, the relationship between BUN and fertility of Korean Holsteins has been demonstrated differently; BUN was lower, especially in the postpartum period in non-cycling cows (Jeong et al, 2015). In our study, BUN concentration was lowest in PRB and highest in NRB. The highest level of NRB could be the result of its harmful effect on conception. However, in the comparison of PNC and PRB, PRB showed a lower level than PNC; a different result was shown com- 
pared with Kurykin et al (2011). This could be the result of the case controls; in Kurykin's research, NRB cows were compared with early lactation cows. The present study indicated that BUN is not associated with fertility.

Many studies have demonstrated lower GLU in RB Holsteins, crossbred cows, and buffaloes (Yadav et al, 1995; Sabasthin et al, 2012; Guzel and Tanriverdi, 2014; Ahmed et al, 2017). In our research, there were no differences in GLU levels in each group, but the lowest level was observed in NRB. Interestingly, the relationship between GLU and fertility remains controversial. Plasma glucose concentrations were higher in cows with a longer calving to conception interval (>150 days) compared to those with shorter calving periods (Bicalho et al, 2017). However, in other studies, these concentrations were higher during the early postpartum period in cows that became pregnant at first insemination than those that failed (Garverick et al, 2013). This follows the result of the latter. The GLU levels in the PNC and PRB groups were similar, but those in the NRB group were lower than those in the other groups. This might be a lesser function of the liver. Considering the results of GGT, lower concentrations of GLU in the NRB group could be the secondary result of impaired gluconeogenesis in the liver.

There is no relationship between TC and RB syndrome, which has already been investigated by some researchers (Guzel and Tanriverdi, 2014; Funeshima et al, 2021). Our results are consistent with those of previous studies. Thus, we founda similar result for domestic Holsteins. However, there is interesting research showing different results with others. In the native Korean Hanwoo breed; the level of TC in RB $(126.78 \pm 5.66 \mathrm{mg} / \mathrm{dL})$ almost double than that of reference range (61.68 $68.72 \mathrm{mg} / \mathrm{dL}$ ) (Yang et al, 1999). This difference could be due to differences in breed or study design. In Hanwoo research, blood was collected from a slaughterhouse, and live RB cows were not compared with NC cows. Moreover, the pregnancy and reproductive cycles of the animals were not controlled, and the breeding conditions were diverse. Research on the relationship be- tween TC and fertility in Holsteins, however, is different from that of TC and RB syndromes. TC was positively associated with the expression of estrus at first ovulation, interval from calving to conception, and likelihood of conception and pregnancy (Westwood et al, 2002).

Several previous studies have reported that NEFA levels are associated with cattle fertility, and cows with fertility problems show high levels of NEFA (Dubuc et al, 2012; Garverick et al, 2013; Jeong et al, 2015). However, in our study, NEFA was not associated with fertility in cows. The PNC group showed wide variations in NEFA levels. This is because this study was conducted in the summer. Heat stress is associated with NEFA (ShehabEl-Deen et al, 2010). Heat stress may outweigh pregnancy. Cows susceptible to heat stress might show high levels of NEFA, regardless of pregnancy.

The limitation of the current study is that we could not categorize cows by the gestation period. In addition, if we had four groups (pregnant $+\mathrm{RB}$, pregnant $+\mathrm{NC}$, non-pregnant $+\mathrm{RB}$, and non-pregnant $+\mathrm{NC}$ ), we could compare the differences among groups. However, we established three groups, one NC and two RB groups, and we could not define the fourth group (non-pregnant $+\mathrm{NC})$ in this study due to the age and parity of the cows. Moreover, we depended on natural observations during the estrous period, rather than synchronizing the reproduction cycle among the animals. However, to the best of our knowledge, this is the first field study to investigate serum biochemical parameters during pregnancy or repeat breeding. Our findings could help increase the fertility of dairy cows.

\section{ACKNOWLEDGEMENTS}

We thanks to the technicians of laboratory, Yeongso Hong, Jihyeon Lee and Nuri Baek. We also extend our thanks to the Sanghoon Park, Jeongju Kim and SeungHak Jung, who helped us collect samples. This work was conducted with the support of "Study on developing behavioral and reproductive indices for evaluation of lactating cow's heat stress (Project No. PJ01429503)" 
project of the National Institute of Animal Science, Rural Development Administration, Republic of Korea.

\section{CONFLICT OF INTEREST}

No potential conflict of interest relevant to this article was reported.

\section{ORCID}

Moo Young Jung, https://orcid.org/0000-0001-7396-6787

Seogjin Kang, https://orcid.org/0000-0001-7838-9042

Dong-Hyun Lim, https://orcid.org/0000-0002-8575-0198

Tae-Il Kim, https://orcid.org/0000-0003-0532-6010

Kyoungseok Lee, https://orcid.org/0000-0003-3743-0007

Seungmin Ha, https://orcid.org/0000-0002-5152-1979

\section{REFERENCES}

Ahmed ME, Ahmed FO, Frah EAM, Elfaki I. 2017. Blood biochemical profile of Sudanese crossbred repeat breeder cows. Afr J Biotechnol 16: 366-370.

Ambrose JD, Drost M, Monson RL, Rutledge JJ, Leibfried-Rutledge ML, Thatcher MJ, Kassa T, Binelli M, Hansen PJ, Chenoweth PJ, Thatcher WW. 1999. Efficacy of Timed Embryo Transfer with Fresh and Frozen In Vitro Produced Embryos to Increase Pregnancy Rates in Heat-Stressed Dairy Cattle1. J Dairy Sci 82: 2369-2376.

Amle M, Patodkar V, Shelar R, Birade H. 2014. Serum biochemical levels of repeat breeder cross bred cows under rural condition of Satara District of Maharashtra. Int. J. Adv. Vet. Sci. Technol 3: 109113.

Båge R, Gustafsson H, Larsson B, Forsberg M, Rodriguez-Martinez H. 2002. Repeat breeding in dairy heifers: follicular dynamics and estrous cycle characteristics in relation to sexual hormone patterns. Theriogenology 57: 2257-2269.

Bicalho M, Marques E, Gilbert R, Bicalho R. 2017. The association of plasma glucose, BHBA, and NEFA with postpartum uterine diseases, fertility, and milk production of Holstein dairy cows. Theriogenology 88: 270-282.

Bonneville-Hébert A, Bouchard E, Tremblay DD, Lefebvre R. 2011. Effect of reproductive disorders and parity on repeat breeder status and culling of dairy cows in Quebec. Can J Vet Res 75: 147-151.

Butler W, Calaman J, Beam S. 1996. Plasma and milk urea nitrogen in relation to pregnancy rate in lactating dairy cattle. J Anim Sci 74: 858-865.

Dawuda P, Scaramuzzi R, Leese H, Hall C, Peters A, Drew S, Wathes D. 2002. Effect of timing of urea feeding on the yield and quality of embryos in lactating dairy cows. Theriogenology 58: 1443-1455.

Dochi O, Takahashi K, Hirai T, Hayakawa H, Tanisawa M, Yamamoto Y, Koyama H. 2008. The use of embryo transfer to produce pregnancies in repeatbreeding dairy cattle. Theriogenology 69: 124-128.

Dubuc J, Duffield T, Leslie K, Walton J, LeBlanc S. 2012. Risk factors and effects of postpartum anovulation in dairy cows. J Dairy Sci 95: 1845-1854.

Funeshima N, Miura R, Katoh T, Yaginuma H, Kitou T, Yoshimura I, Konda K, Hamano S, Shirasuna K. 2021. Metabolomic profiles of plasma and uterine luminal fluids from healthy and repeat breeder Holstein cows. BMC Veterinary Research 17: 54.

García-Ispierto I, López-Gatius F, Santolaria P, Yániz JL, Nogareda C, López-Béjar M. 2007. Factors affecting the fertility of high producing dairy herds in northeastern Spain. Theriogenology 67: 632638.

Garverick H, Harris M, Vogel-Bluel R, Sampson J, Bader J, Lamberson W, Spain J, Lucy M, Youngquist R. 2013. Concentrations of nonesterified fatty acids and glucose in blood of periparturient dairy cows are indicative of pregnancy success at first insemination. J Dairy Sci 96: 181-188.

Grala TM, Kuhn-Sherlock B, Roche JR, Jordan OM, Phyn CVC, Burke CR, Meier S. 2021. Changes in plasma electrolytes, minerals, and hepatic markers of health across the transition period in dairy 
cows divergent in genetic merit for fertility traits and postpartum anovulatory intervals. J Dairy Sci. doi:10.3168/jds.2021-20783.

Guzel S, Tanriverdi M. 2014. Comparison of serum leptin, glucose, total cholesterol and total protein levels in fertile and repeat breeder cows. Rev Bras Zootec 43: 643-647.

Jeong J, Choi I, Kang H, Hur T, Jung Y, Kim I. 2015. Relationship between serum metabolites, body condition, peri-and postpartum health and resumption of postpartum cyclicity in dairy cows. Livest Sci 181: 31-37.

Katagiri S, Moriyoshi M. 2013. Alteration of the endometrial EGF profile as a potential mechanism connecting the alterations in the ovarian steroid hormone profile to embryonic loss in repeat breeders and high-producing cows. Journal of Reproduction and Development 59: 415-420.

Kurykin J, Waldmann A, Tiirats T, Kaart T, Jaakma Ü. 2011. Morphological quality of oocytes and blood plasma metabolites in repeat breeding and early lactation dairy cows. Reprod Domest Anim 46: 253-260.

Lucy MC. 2001. Reproductive Loss in High-Producing Dairy Cattle: Where Will It End? J Dairy Sci 84: 1277-1293.

Meissonnier E, Rousseau P. 1976. les tests enzymatiques dans l'exploration fonctionnelle du foie chez les bovins, In: Reports and Abstracts of the 9th fnternational Congress of diseases of cattle, pp. 633636.

Omer F. 2008. THE EFFICACY OF INTRA-UTERINE INFUSION OF IODINE COMPOUNDS ON THE REPRODUCTIVE EFFICIENCY OF POSTPARTUM AND REPEAT BREEDER CROSS-BRED DAIRY COWS IN THE SUDAN.
Rajala-Schultz P, Saville W, Frazer G, Wittum T. 2001. Association between milk urea nitrogen and fertility in Ohio dairy cows. J Dairy Sci 84: 482-489.

Sabasthin A, Kumar VG, Nandi S, Murthy VC. 2012. Blood haematological and biochemical parameters in normal cycling, pregnant and repeat breeding buffaloes (Bubalus bubalis) maintained in isothermic and isonutritional conditions. Asian Pac J Reprod 1: 117-119.

Samarütel J, Ling K, Waldmann A, Jaakson H, Kaart T, Leesmäe A. 2008. Field trial on progesterone cycles, metabolic profiles, body condition score and their relation to fertility in Estonian Holstein dairy cows. Reprod Domest Anim 43: 457-463.

Shehab-El-Deen MAM, Fadel MS, Van Soom A, Saleh SY, Maes D, Leroy JL. 2010. Circadian rhythm of metabolic changes associated with summer heat stress in high-producing dairy cattle. Trop Anim Health Prod 42: 1119-1125.

Sinclair K, Kuran M, Gebbie F, Webb R, McEvoy T. 2000. Nitrogen metabolism and fertility in cattle: II. Development of oocytes recovered from heifers offered diets differing in their rate of nitrogen release in the rumen. J Anim Sci 78: 2670-2680.

Westwood C, Lean I, Garvin J. 2002. Factors influencing fertility of Holstein dairy cows: a multivariate description. J Dairy Sci 85: 3225-3237.

Yadav NK, Lohan JS, Singh B, Chand D. 1995. Studies on some serum constituents in anoestrous buffaloes. Indian J Anim Res 29: 85-88.

Yang BK, Kim JB, Cheong HT, Park CK, Kim CI, Hwang HS, Kim HK. 1999. Analysis of Blood Chemical Values and Hormone of Repeat Breeder and Reproductive Disorder in Hanwoo. Reprod Dev Biol 23: 175-180. 